\title{
The Rate and Mechanism of Long Chain 2, 3-Dialkyl Acroleins Formation in Meat by Heat Treatment ${ }^{\dagger}$
}

\author{
Takeo Nakanishi and Kyozo Suyama \\ Laboratory of Animal Products Technology, Faculty of Agriculture, Tohoku University, \\ Sendai, Japan
}

Received October 20,1972

\begin{abstract}
The long chain $\left(\mathrm{C}_{24} \sim \mathrm{C}_{36}\right)$ 2,3-dialkyl acroleins in heated meat were produced by aldol condensation and dehydration reaction of fatty aldehyde via hydrolysis of plasmalogen. This work was undertaken to determine the rate of aldol condensation of fatty aldehyde under various temperatures. Two-dimentional thin-layer chromatography for determining the plasmalogen-aldehyde, free fatty aldehyde and 2,3-dialkyl acrolein in heated meat was also described. The reaction-rate data indicated that it appeared to be reasonable to assume the following complex reaction including consecutive and competitive reaction mechanism as an over-all picture of the reaction. However at higher temperatures the reaction was found to be more complex than at lower temperature.
\end{abstract}

$$
\begin{array}{ll}
\text { Plasmalogen-aldehyde } \stackrel{k_{1}}{\longrightarrow} \text { Free fatty aldehyde } \\
\text { Free fatty aldehyde } \stackrel{k_{2}}{\longrightarrow} \text { 2,3-Dialkyl acrolein } \\
\text { Free fatty aldehyde } \stackrel{k_{3}}{\longrightarrow} \text { Unidentified compounds }
\end{array}
$$

The apparent energy and entropy of activation for long chain 2,3-dialkyl acrolein formation were calculated to be $10.1 \mathrm{kcal} /$ mole and $-49.8 \mathrm{cal} / \mathrm{deg} \cdot \mathrm{mole}$, respectively. The large negative entropy of activation could be explained that the number of degrees of freedom were decreased by this reaction. From a view point of energy of activation, aldol condensation in heated meat was relatively easy to occur.

The amino groups acts as a basic catalyst in the aldol condensation of the carbonyl compounds, followed by dehydration of the condensation products to yield the alk-2-enals." It has previously been reported ${ }^{2}$ that the condensation of aldehydes to alk-2-enals was catalyzed by phospholipids which contained amino group. Montgomery and Day ${ }^{33}$ suggested that aldol condensation reaction led to the formation of flavor compounds and polymeric pigments in foods. Burton et al ${ }^{4,53}$ also showed that the development of alk-2enals in many foods were probably the first step in chromophores development.

We have shown recently ${ }^{6}$, that the long chain $\left(\mathrm{C}_{24} \sim \mathrm{C}_{36}\right)$ 2,3-dialkyl acroleins (abbreviated as DAA) were formed in chicken,

\footnotetext{
+ Studies on Phospholipids of Meat. Part XI For the previous paper, Part $\mathrm{X}$, see reference 6).
}

pork and beef by heat treatment, and DAA were produced by aldol condensation reaction of fatty aldehyde (abbreviated as F-Al) via hydrolysis of plasmalogen. This result suggested that aldol condensation reaction occurred in meat or meat products during storage or heat processing.

The purpose of this paper is to obtain information of the kinetic behavior of these reactions in meat. For this purpose, we describe in this paper the determination of the rate of aldol condensation of $\mathrm{F}-\mathrm{Al}$ under various temperatures and the elucidation of the rate laws for disappearance of aldehyde in plasmalogen (abbreviated as $\mathrm{Pl}-\mathrm{Al}$ ), the production and disappearance of $\mathrm{F}-\mathrm{Al}$, and the production of DAA in meat.

Two-dimentional thin-layer chromatographic procedure for determining the $\mathrm{Pl}-\mathrm{Al}$, 
$\mathrm{F}-\mathrm{Al}$ and DAA contents in heated meat is also described.

\section{EXPERIMENTAL}

1. Solvents and reagents. All the solvents used were of reagent grade quality. By dissolving $\mathrm{HCl}$ gas, an approximately $3 \% \mathrm{HCl}$ solution in methanol was prepared, in which commercial pure 2,4-dinitrophenyl hydrazine was dissolved to concentration of $2 \%$ (DNP-reagent).

2. Materials. Sample of muscle was taken from $M$. longissimus dorsi section of pig after about 1 day of slaughter.

3. Preparation of heated meat. Twenty grams of $M$. longissimus dorsi of pig was placed in the test tube (hard glass, thick-wall, $1.4 \times 20 \mathrm{~cm}$ ). After the atmosphere was replaced by nitrogen gas, the tube was flame-sealed to prevent evaporation and oxidation during reaction at elevated temperature. The sealed tube was placed in a temperature-controlled oil bath at the desired temperatures $\left( \pm 1^{\circ} \mathrm{C}\right)$. After heating, the tube was placed in dry ice-ethanol and stored in this solution until required.

4. Extraction of lipids. The procedure of Folch et al. ${ }^{7 !}$ was used for extraction of lipids. The sample was homogenized in $300 \mathrm{ml}$ of chloroform-methanol $(2: 1 \mathrm{v} / \mathrm{v})$ in a high speed blender (Nippon seiki). After standing for $15 \mathrm{~min}$ with stirring, the suspension was filtered through filter paper on a Büchner funnel. The filtrate was shaken for $2 \sim 3 \mathrm{~min}$ with 0.2 volume of $0.9 \%$ $\mathrm{NaCl}$ solution. After standing it for about $1 \mathrm{hr}$ at $00^{\circ} \mathrm{C}$, the separated lower layer was evaporated to dryness in vacuo, and dissolved in $10 \mathrm{ml}$ of chloroform.

5. Preparation of thin-layer plates. Glass plates $(20 \times 20 \mathrm{~cm})$ were coated with Silica Gel H (E. Merck) to a thickness of about $300 \mu$ using a thin-layer applicator (Toyo Kagaku). The plates, after air-drying at room temperature, were activated in an air-oven at $120^{\circ} \mathrm{C}$ for $2 \mathrm{hr}$.

6. Two-dimentional thin-layer chromatography. One hundred and fifty $\mu$ l of the solution of extracted lipid in chloroform was spotted, at the lower left hand corner, $2 \mathrm{~cm}$ from each side of a thin-layer plate by $50 \mu 1$ volumetric micro syringe (Jintan Co., Japan, for gas chromatography) (Fig. 1). The plate was developed to height of $12 \sim 15 \mathrm{~cm}$ in TLC chamber containing $n$-hexan-ethyl ether $(90: 10 \mathrm{v} / \mathrm{v})$ as a developing solvent. The plate was removed from the TLC chamber and dried with a stream of dry nitrogen. A strip of $4 \mathrm{~cm}$ wide at the left side of the plate was then sprayed in excess with a DNP-reagent (Fig. 1) for quantitative

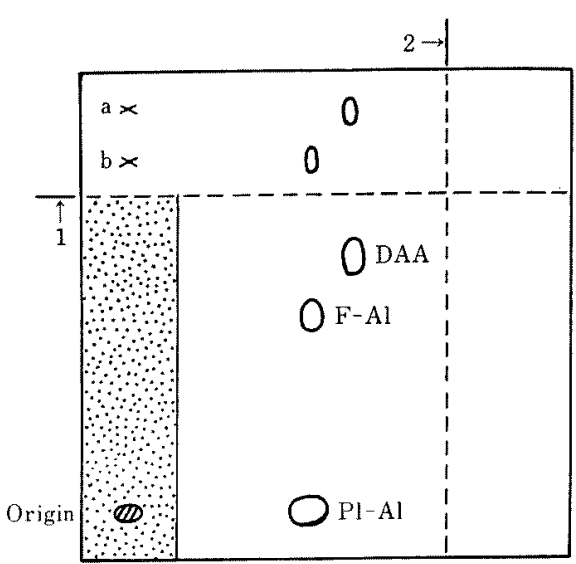

Fig. 1. Tracing of Two Dimensional Thin-layer Chromatogram of DNP-Hydrazones of Plasmalogenaldehyde(Pl-Al), Free Fatty Aldehyde(F-Al) and 2,3Dialkyl Acrolein (DAA).

$a=$ Spot of 2-tetradecyl-2-octadecenal DNPH as reference standard

$\mathrm{b}=$ Spot of hexadecyl aldehyde DNPH as reference standard

$1=$ Solvent front for the development in the first dimention

$2=$ Solvent front for the development in the second dimension

$\because \because \because=$ Area sprayed with DNP-reagent.

Experimental details were given in the text.

formation of DNP-hydrazone of Pl-Al, F-Al and DAA, and then dried for 10 min under a stream of dry nitrogen in TLC chamber which contained calcium chloride. In our earlier work, ${ }^{8 /}$ formation of DNP-hydrazones of these compounds on TLC plate was shown to be quantitative.

As reference standards, DNP-hydrazones of palmitoaldehyde and 2-tetradecyl-2-octadecenal were spotted at the upper left hand corner of the plate, and then developed in second dimension with developed components in the first dimension from a left edge with the same $n$-hexan-ethyl ether $(90: 10 \mathrm{v} / \mathrm{v})$ as a developing solvent. When the solvent rose to a height of about $15 \mathrm{~cm}$, the plate was removed from the chamber and dried in atmosphere. Thus, the position of yellow spots of DNP-hydrazones of Pl-Al and F-Al, and orange colour spot of DNP-hydrazone of DAA were detected.

7. Quantification of DNP-hydrazones. Each outlined spot of each DNP-hydrazones was scraped directly into the glass stoppered centrifuge tube of $10 \mathrm{ml}$ volume, to which $10 \mathrm{ml}$ or $5 \mathrm{ml}$ of chloroform was added, and then centrifuged at 1,000 rpm for $5 \mathrm{~min}$ after shaking. The absorbances of the upper chloroform solution of DNP-hydrazones of Pl-Al and F-Al 
were determined at $358 \mathrm{~m} \mu$ and that of DAA was determined at $382 \mathrm{~m} \mu$ in $1 \mathrm{~cm}$ cells against a blank prepared in the absence of DNP-hydrazone. with Hitachi-Perkin Elmer 139 spectrophotometer. The concentrations of Pl-Al and F-Al, and DAA were calculated from a molar absorptivity of 21,600 , and 29,000 described in our previous reports, $, 8,9$ respectively.

\section{RESULTS AND DISCUSSION}

\section{Reproducibility of the method}

The results of the analysis of $\mathrm{Pl}-\mathrm{Al}, \mathrm{F}-\mathrm{Al}$ and DAA contents in five samples heated under the same condition (at $100^{\circ} \mathrm{C}$ for $4 \mathrm{hr}$ ) were presented in Table I. The values of mean, variance, standard deviation and coefficient of variation of five measurements were presented in Table I. The statistical data showed satisfactory reproducibilities among five measurements.

TABle I. REPRODUCIBILITY OF THE METHOD

The values of $\mathrm{Pl}-\mathrm{Al}$ and $\mathrm{F}-\mathrm{Al}$, and DAA were absorbancy at 358 , and $382 \mathrm{~m} \mu$ of DNP-hydrazine derivatives, respectively. The samples were heated at $100^{\circ} \mathrm{C}$ for $4 \mathrm{hr}$. Experimental details were given in the text.

\begin{tabular}{lllll}
\hline & $\begin{array}{c}\text { Run } \\
\text { No. }\end{array}$ & Pl-Al & F-Al & DAA \\
& 1 & 0.302 & 0.090 & 0.155 \\
2 & 0.324 & 0.083 & 0.169 \\
& 3 & 0.315 & 0.091 & 0.150 \\
& 4 & 0.298 & 0.096 & 0.149 \\
Mean & 5 & 0.334 & 0.085 & 0.178 \\
Variance & 0.315 & 0.089 & 0.160 \\
Standard deviation & 0.00134 & 0.0046 & 0.0114 \\
Coefficient of & 0.043 & 0.052 & 0.071 \\
variation & & & \\
\hline
\end{tabular}

2. Relationships between $P l-A l, F-A l$ and $D A A$ concentrations and heating times at various temperatures

At heating temperatures of $100^{\circ} \mathrm{C}, 110^{\circ} \mathrm{C}$, $120^{\circ} \mathrm{C}$ and $130^{\circ} \mathrm{C}$, the relations of the concentrations calculated as molar fractions of $\mathrm{Pl}-\mathrm{Al}, \mathrm{F}-\mathrm{Al}$, DAA and UIC to the heating times were shown in Fig. 2, 3, 4 and 5, respectively. UIC should be the sum of all possible reaction products and calculated

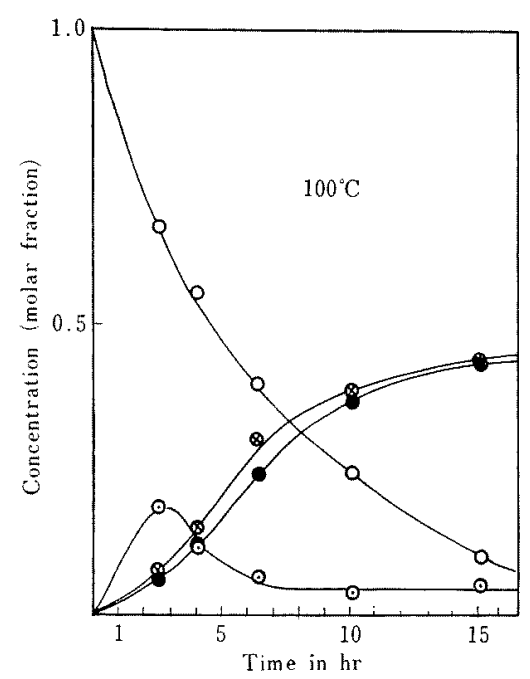

FIG, 2. The Change in Concentrations of Plasmalogen-aldehyde (Pl-Al), Free Fatty Aldehyde (F-Al) and 2,3-Dialkyl Acrolein (DAA) with Time Heated at $100^{\circ} \mathrm{C}$ of $\mathrm{Pig} M$. longissimus dorsi.

$\odot-\mathrm{Pl}-\mathrm{Al} ; \odot-\odot, \mathrm{F}-\mathrm{Al} ; \bullet-\mathrm{DAA} ; \otimes-\otimes, \mathrm{UIC}$.

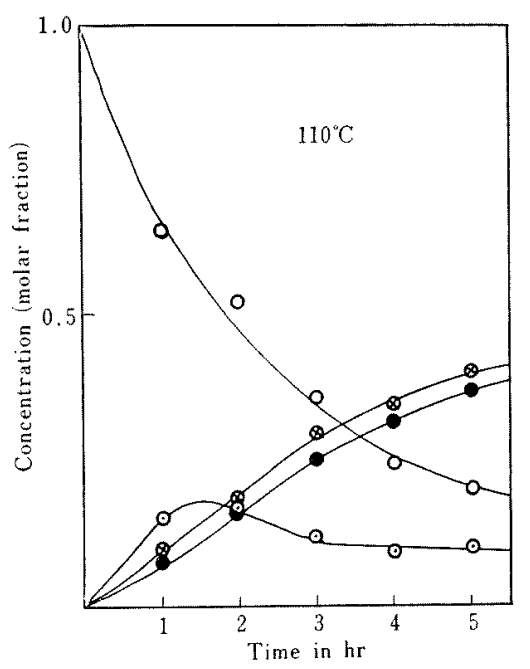

FIG. 3. The Change in Concentrations of Plasmalogen-aldehyde ( $\mathrm{Pl}-\mathrm{Al}$ ), Free Fatty Aldehyde (F-Al) and 2,3-Dialkyl Acrolein (DAA) with Time Heated at $110^{\circ} \mathrm{C}$ of Pig $M$. longissimus dorsi.

$\mathrm{O}-\mathrm{O}, \mathrm{Pl}-\mathrm{Al} ; \odot-\odot, \mathrm{F}-\mathrm{Al} ; \bullet-\bullet, \mathrm{DAA} ; \ominus-\bigcirc, \mathrm{UIC}$.

as follows;

$$
[\mathrm{UIC}]=A_{0}-[\mathrm{Pl}-\mathrm{Al}]-[\mathrm{F}-\mathrm{Al}]-[\mathrm{DAA}]
$$

Where $A_{0}$ represents initial concentration of Pl-Al.

From experimental finding (Figs. 2, 3, 4, 


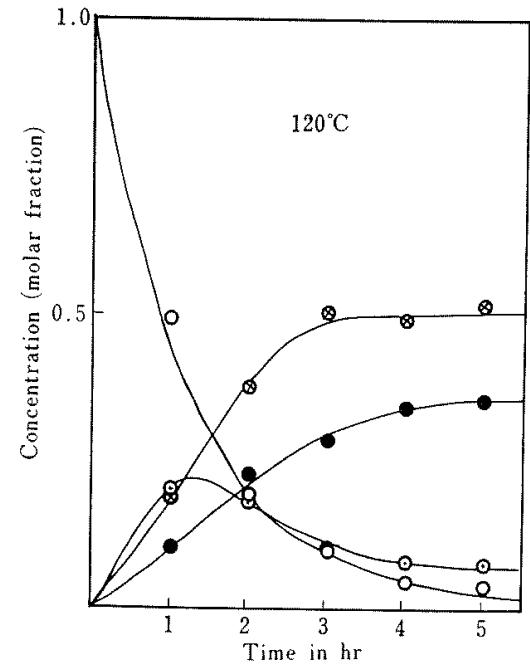

Frg. 4. The Change in Concentration of Plasmalogen-aldehyde (Pl-Al), Free Fatty Aldehyde (F-Al) and 2,3-Dialky Acrolein (DAA) with Time Heated at $120^{\circ} \mathrm{C}$ of $\mathrm{Pig} M$. longissimus dorsi.

$\bigcirc-0, \mathrm{Pl}-\mathrm{Al} ; \odot-\odot, \mathrm{F}-\mathrm{Al} ; \bullet-\bullet, \mathrm{DAA} ; \otimes-\odot, \mathrm{UIC}$.

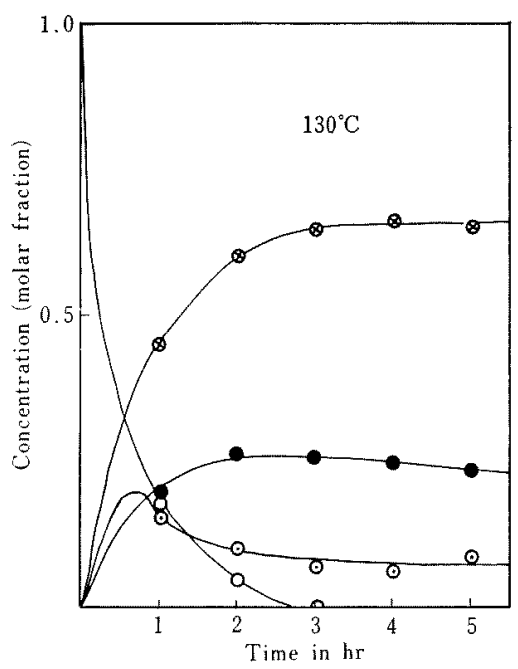

FIG. 5. The Change in Concentrations of Plasmalogen-aldehyde (Pl-Al), Free Fatty Aldehyde (F-Al) and 2,3-Dialkyl Acrolein (DAA) with Time Heated at $130^{\circ} \mathrm{C}$ of $\mathrm{Pig} M$. longissimus dorsi.

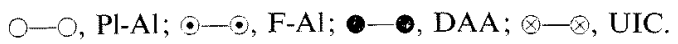

and 5), following assumptions may be made to define the kinetic behaviour of the reactions.

1) Rate of disappearance of $\mathrm{Pl}-\mathrm{Al}$. Figure 6 gives curves showing the logarithm of the

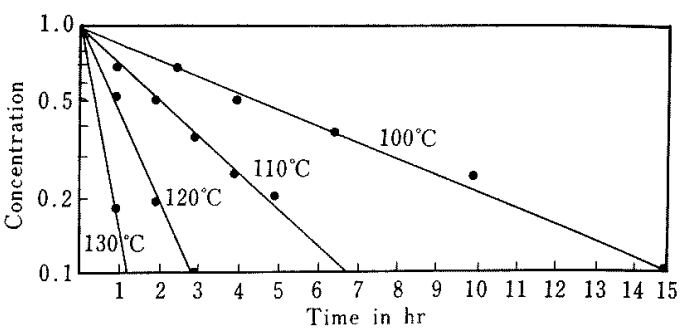

FIG. 6. The Change in $\mathrm{Pl}-\mathrm{Al}$ Concentration with Time Heated at Various Temperatures.

concentrations of $\mathrm{Pl}-\mathrm{Al}$ as a function of the time at $100^{\circ} \mathrm{C}, 110^{\circ} \mathrm{C}, 120^{\circ} \mathrm{C}$ and $130^{\circ} \mathrm{C}$ (firstorder plots of disappearance of $\mathrm{Pl}-\mathrm{Al}$ ). The linear relationships of every heat treatments were obtained. This result meant that $\mathrm{Pl}-\mathrm{Al}$ disappeared according to a first order reactions, that is, $\mathrm{F}-\mathrm{Al}$ formation was regarded as simple first-order term with respect to $\mathrm{Pl}-\mathrm{Al}$.

2) Change of F-Al concentration. From $\mathrm{F}-\mathrm{A} 1$ concentration-heating time curves of Figs. 2, 3, 4 and 5, maximum concentrations of $\mathrm{F}-\mathrm{Al}$ were observed in every cases. The result obtained meant that $\mathrm{F}-\mathrm{Al}$ was considered to be an intermediate in a consecutive reaction.

3) Change of $D A A$ concentration. From the curves in Figs. 2, 3, 4 and 5, DAA concentrations increased in the time course, but the slope of curves became sluggish and finaly equilibrated. Discussion of this point would be described later. However, in the case of $130^{\circ} \mathrm{C}$ treatment (Fig. 5), DAA concentration slightly decreased at the final stage. This observation suggested that $\mathrm{DAA} \longrightarrow \mathrm{UIC}$ reaction occurred in meat by heat treatment at higher temperature but the rate of its reaction was very slow. Burton et al. ${ }^{5}$ showed that $\alpha, \beta$-unsaturated straight chain aldehydes greatly accelerated by initial development of chromophores in foods, but this effect was not shown by the unsaturated aldehydes with alkyl substituent on the $a$-carbon atom (2,3dialkyl acroleins). On the basis of these data, DAA seemed to be stable in meat.

The aldol condensation reaction in the presence of basic catalyst in general $^{10)}$ was 
first order term with respect to aldehyde, and that in the presence of amine or phosphatidyl ethanolamine ${ }^{11}$ was also first order term with respect to aldehyde. On the basis of these data, it seemed to be reasonable to assume that DAA formation followed first order term with respect to $\mathrm{F}-\mathrm{Al}$.

4) Change of UIC concentration. The reaction of UIC formation from DAA takes place, but the rate of this reaction was small enough to be neglected as previously described. This illustrated that the reaction of F-Al with meat components (such as amino group) produced UIC. On the other hand, the rate curves of formation reaction of UIC shown in Figs. 2, 3, 4 and 5 were qualitatively the same as the rate curves of DAA formation reaction. We assumed that UIC formation followed first order term with respect to $\mathrm{F}-\mathrm{Al}$.

3. Mechanism of the reaction and kinetic analysis

In the establishing an approximate kinetic scheme fitting the data given in Figs. 2, 3, 4 and 5 , certain approximates were unavoidable because of the complexity of the reaction and the unavailability of information on the structure of UIC as described in above section.

It seems to be reasonable to assume from the discussion of the above section that the following complex reactions including consecutive and competitive reaction mechanisms appears as an over-all picture of the reaction.

$$
\begin{aligned}
& \mathrm{Pl}-\mathrm{Al} \stackrel{k_{1}}{\longrightarrow} \mathrm{F}-\mathrm{Al} \\
& \mathrm{F}-\mathrm{Al} \stackrel{k_{2}}{\longrightarrow} \mathrm{DAA} \\
& \mathrm{F}-\mathrm{Al} \stackrel{k_{3}}{\longrightarrow} \mathrm{UIC}
\end{aligned}
$$

Where $k_{1}, k_{2}$ and $k_{3}$ are the rate constants. The reverse reactions are not written in above scheme, although the posibility of these reactions can not be disregarded. The rate laws which are assumed to be applied to proposed mechanism are expressed by the following differential equations:

$$
\begin{gathered}
d[\mathrm{Pl}-\mathrm{Al}] / d t=-k_{1}[\mathrm{Pl}-\mathrm{Al}] \\
d[\mathrm{DAA}] / d t=k_{2}[\mathrm{~F}-\mathrm{Al}] \\
d[\mathrm{UIC}] / d t=k_{3}[\mathrm{~F}-\mathrm{Al}] \\
d[\mathrm{~F}-\mathrm{Al}] / d t=k_{1}[\mathrm{Pl}-\mathrm{Al}]-\left(k_{2}+k_{3}\right)[\mathrm{F}-\mathrm{Al}] \\
{[\mathrm{DAA}]+[\mathrm{UIC}]=A_{0}-[\mathrm{Pl}-\mathrm{Al}]-[\mathrm{F}-\mathrm{Al}]}
\end{gathered}
$$

integration of eq. (4) gives

$$
[\mathrm{Pl}-\mathrm{Al}]=A_{0} \exp \left(-k_{1} t\right)
$$

and then eq. (7) becomes

$$
[\mathrm{F}-\mathrm{Al}]=\frac{A_{0} k_{1}}{m_{1}} \exp \left(-m_{2} t\right)-\exp \left(-k_{1} t\right)
$$

substituting eq. (9) and (10) into eq. (8) we get

$$
\begin{gathered}
{[\mathrm{DAA}]+[\mathrm{UIC}]=A_{0}\left\{1+\frac{m_{2}}{m_{1}} \exp \left(-k_{1} t\right)\right.} \\
\left.-\frac{k_{1}}{m_{1}} \exp \left(-m_{2} t\right)\right\}
\end{gathered}
$$

from eq. (5) and (6)

$$
[\mathrm{DAA}] /[\mathrm{UIC}]=k_{2} / k_{3}
$$

substituting eq. (12) into eq. (11) we get

$$
\begin{gathered}
{[\mathrm{DAA}]=A_{0}\left\{\frac{k_{2}}{m_{2}}+\frac{k_{2}}{m_{1}} \exp \left(-k_{1} t\right)\right.} \\
\left.-\frac{k_{1} k_{2}}{m_{1} m_{2}} \exp \left(-m_{2} t\right)\right\}
\end{gathered}
$$

and

$$
\begin{gathered}
{[\mathrm{UIC}]=A_{0}\left\{\frac{k_{3}}{m_{2}}+\frac{k_{3}}{m_{1}} \exp \left(-k_{1} t\right)\right.} \\
\left.-\frac{k_{1} k_{3}}{m_{1} m_{2}} \exp \left(-m_{2} t\right)\right\}
\end{gathered}
$$

where

$$
\begin{gathered}
m_{1}=k_{1}-\left(k_{2}+k_{3}\right) \\
m_{2}=k_{2}+k_{3}
\end{gathered}
$$

Assuming that the reactions are not reversible, the apparent first order rate constants are calculated from the data in Figs. 2, 3, 4 and 5 , and are presented in Table II. A value of $k_{1}$ is calculated from equation (9), values of $k_{2}$ and $k_{3}$ are calculated from equation (10), (13) and (14). Figure 7 is plot of data which are computed upon the illustrative 
assumption that the values of the parameters are $A_{0}=1.0$ and rate constants described in Table II. The good agreements of the computative curve (Fig. 7) with experimental curves (Figs. 2, 3, 4 and 5) are obtained. From

Table II. Apparent First-order RATE CONSTANTS

\begin{tabular}{cccc}
\hline$t(\mathrm{C})$ & $\begin{array}{c}k_{1}\left(\mathrm{sec}^{-1}\right. \\
\left.10^{5}\right)\end{array}$ & $\begin{array}{c}k_{2}\left(\mathrm{sec}^{-1}\right. \\
\left.\times 10^{5}\right)\end{array}$ & $\begin{array}{c}k_{3}\left(\mathrm{sec}^{-1}\right. \\
\left.10^{5}\right)\end{array}$ \\
\hline $\left.100^{a}\right)$ & 4.16 & 11.1 & 9.72 \\
$110^{b 3}$ & 9.72 & 15.0 & 16.4 \\
$120^{b}$, & 22.2 & 24.4 & 42.5 \\
$\left.130^{b}\right)$ & 39.4 & 30.6 & 61.7 \\
\hline
\end{tabular}

a) = mean values of deta for 1.5 and $4 \mathrm{hr}$.

b3 = mean values of data for 1 and $2 \mathrm{hr}$.

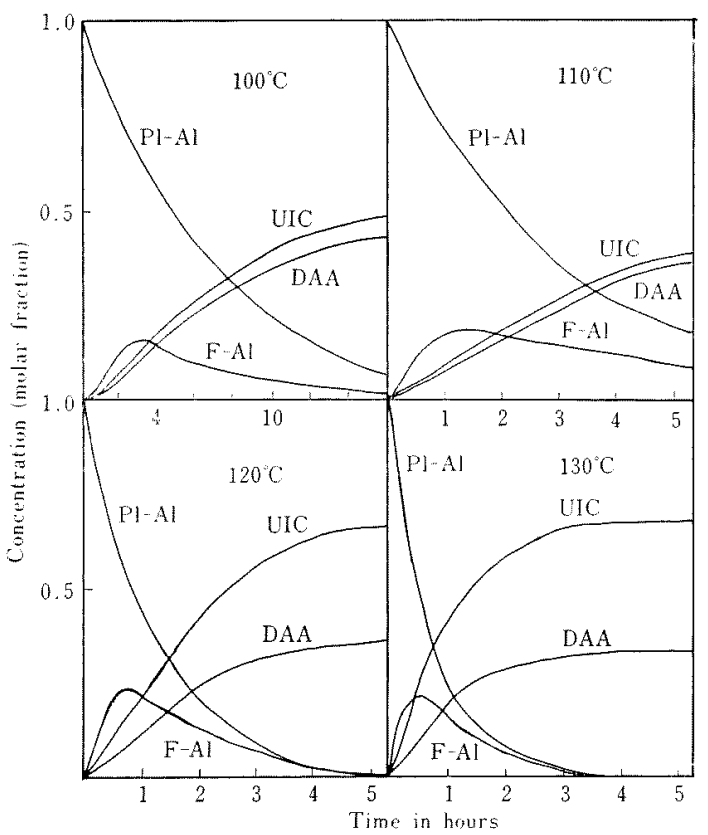

Fig. 7. The Computative Curve of the Changing Concentration of Pl-Al, F-Al, DAA and UIC vs. Heating time.

The values of the paramaters were $A_{0}=1.0$ and rate constants described in Table II.

a consideration of above results, it seems that experimental measurements interpreted the theoretical scope and mechanism, except that following several differences are observed between experimental curves and computative curves, especially in the case of $120^{\circ} \mathrm{C}$ and $130^{\circ} \mathrm{C}$ treatments.

a) Experimental curves show that $\mathrm{F}-\mathrm{Al}$ concentration do not become zero as illustrated in computative curves, and final concentrations of F-Al, DAA and UIC approach constant values. From these reasons, following two assumptions may be made to define the kinetic behavior or reaction. First, the reverse reactions occurred. Second, degradation of functional groups such as amino groups participating the aldol condensation reaction occurred. Further aspect of mechanism will be presented in next paper. ${ }^{11)}$

b) A slight decrease of DAA concentration occurred in the case of $130^{\circ} \mathrm{C}$. This observation suggested that $\mathrm{DAA} \longrightarrow \mathrm{UIC}$ reaction actually occurred, but rate constant of this reaction is small enough to be neglected as previously described.

4. Thermodynamic quantities of the activation

The effect of temperature on the rates of reactions is revealed by Arrhenius plots of $\log k_{1}, k_{2}$ and $k_{3}$ vs. the reciprocal of the absolute temperature, $T$ (Fig. 8). The straight

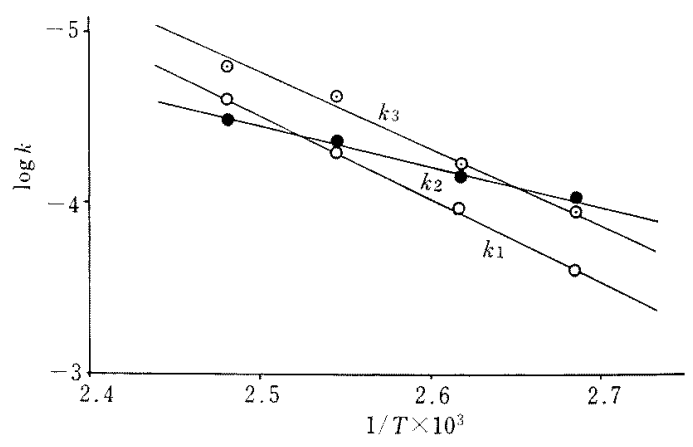

FIG. 8. Arrhenius Plots.

Temperature dependence of rate constants $k_{1}, k_{2}$ and $k_{3}$.

lines are obtained. The validity of the observed rate constants, $k_{1}, k_{2}$, and $k_{3}$ are established by the linearity of the Arrhenius plots.

The energies of activation $\left(E_{a}\right)$ are calculated for the slopes of the lines obtained using the formula $E_{a}=-2.3026 \mathrm{R}$ (slope). The frequency factor $(A)$ and entropy of activation $\left(\Delta S^{\ddagger}\right)$ are also calculated from the equation 
$\log A=\log k-($ slope $/ T)$ and $A=(K T / h) \exp$ $\left(\mathcal{H} S^{*} / R\right)$, respectively. A summary of these results are provided in Table III.

Table III. Thermodynamic Quantities of THE ACtIVATION

\begin{tabular}{cccc}
\hline Reaction & $\begin{array}{c}E_{a}\left(\mathrm{kcal}^{2}\right. \\
\left.\mathrm{mole}^{-1}\right)\end{array}$ & $A\left(\mathrm{sec}^{-1}\right)$ & $J S^{*}$ \\
\hline $\mathrm{Pl}-\mathrm{Al} \stackrel{k_{1}}{\longrightarrow}$ F-Al & 22.0 & $3.2 \times 10^{8}$ & -20.1 \\
$\mathrm{~F}-\mathrm{Al} \stackrel{k_{2}}{\longrightarrow}$ DAA & 10.1 & $1.0 \times 10^{2}$ & -49.8 \\
$\mathrm{~F}-\mathrm{Al} \stackrel{k_{3}}{\longrightarrow}$ UIC & 20.1 & $5.0 \times 10^{7}$ & -23.8 \\
\hline
\end{tabular}

$E_{a}$ is Arrhenius activation energy; $A$ is Arrhenius frequency factor; $A S \neq$ is entropy (in cal $/ \mathrm{deg} \cdot \mathrm{mole}$ ) of activation at $373 \mathrm{~K}$.

It appears from Table III that the reaction has unusually large negative entropy of activation for a first-order reaction, expecially for $\mathrm{F}-\mathrm{Al} \longrightarrow$ DAA reaction $(-49.8$ e.u. $)$, although value of energy of activation is relatively low. The large negative entropy of activation can be explained that the number of degrees of freedom are decreased by the reaction in meat. A decrease in the number of degrees of freedom may depend upon the reaction in meat which is heterogeneous and complex reaction system, and/or large numbers of carbon atoms of $\mathrm{F}-\mathrm{Al}$ molecules, and/ or change of solvation of reactants during the reaction, thereby resulting in a negative entropy of activation. From a view point of energy of activation, these data indicated that the aldol condensation reaction in meat was relatively easy to occur.

\section{REFERENCES}

1) F. H. Westheimer and H. Cohen, J. Amer. Chem. Soc, 60,90 (1938).

2) T. Nakanishi and K. Suyama, Jap. J. Zootech. Sci., 40, 320 (1969).

3) M. W. Montgomery and E. A. Day, J. Food Sci., 30, 828 (1965).

4) H. S. Burton and D. J. McWeeny, Nature, 197, 1080 (1963).

5) H.S. Burton, D. J. McWeeny and D. D. Biltcliff, J. Sci. Food Agr., 14, 911 (1963).

6) T. Nakanishi and K. Suyama, Jap. J. Zootech. Sci., 41, 138 (1970).

7) J. Folch, M. Lees and G. H. Sloan-Stanley, J. Biol. Chem., 222, 497 (1957).

8) T. Nakanishi and K. Suyama, Jap. J. Zootech. Sci., 40, 101 (1969).

9) T. Nakanishi and K. Suyama, ibid., 41, 29 (1970).

10) "Organic Reaction," Vol 16, ed. by R. Adams, A. H. Blatt, V. Boekelheide, T. L. Cairns, A. C. Cope, D. J. Cram, H. O. House, John Wiley and Sons Inc., New York, London, Sydney, 1968, p. 4 .

11) T. Nakanishi and K. Suyama, Nippon Nogeikagaku Kaishi, 47. 313 (1973). 